Original Research Paper

\title{
UJI STABILITAS SEDIAAN HAIR TONIC KOMBINASI EKSTRAK DAUN PANDAN WANGI (Pandanus amarillyfolius) DAN HERBA PEGAGAN (Centella asiatica)
}

\author{
Gina Septiani Agustien*, Ali Nofriyaldi, Srie Rezeki Nur Endah \\ Program Studi Farmasi, Universitas Perjuangan, Jl. Peta No. 77, 46115, Tasikmalaya, Indonesia
}

\section{Email Corresponding:}

ginaagustien@gmail.com

Page : $47-52$

\section{Kata Kunci :}

Formulasi Hair Tonic, Daun Pandan Wangi, Herba Pegagan, Stabilitas

\section{Keywords:}

Hair Tonic Formulation, Pandanus Leaves, Centella, Stability

\section{Published by:}

Tadulako University,

Managed by Faculty of Medicine.

Email: healthytadulako@gmail.com

Phone (WA): +6285242303103

Address:

Jalan Soekarno Hatta Km. 9. City of

Palu, Central Sulawesi, Indonesia

\section{ABSTRAK}

Salah satu tanaman yang secara empiris dapat dimanfaatkan sebagai perawatan rambut adalah pandan wangi (Pandanus amaryllifolius Roxb) dan pegagan (Centella asiatica). Produk kosmetik di pasaran kebanyakan berasal dari produk sintetis berpotensi menyebabkan efek samping seperti pruritus dan iritasi lokal. Bentuk sediaan hair tonik dipilih karena sediaan ini cocok untuk penggunaan topikal pada rambut, lebih mudah pengaplikasiannya dan tidak lengket dibandingkan dengan sediaan semisolid. Penelitian ini bertujuan untuk menguji stabilitas sediaan hair tonic kombinasi ekstrak pandan wangi dan herba pegagan. Formula kombinasi yang digunakan yaitu perbandingan pandan wangi dan pegagan F 1 (kontrol), F II (2:3), F III (2,5:2,5), F IV (3:2). Pengujian stabilitas secara cycling test menunjukan secara oranoleptik semua formula baik, nilai uji $\mathrm{pH}$ antara 5,57-6,16, nilai uji viskositas 2,63-2,83 cps. Hasil penelitian menunjukan bahwa semua formula kombinasi ekstrak pandan wangi dan herba pegagan memenuhi uji stabilitas.

\section{ABSTRACT}

One of the plants that can be used empirically as hair care is pandanus leaves (Pandanus amaryllifolius Roxb) and centella (Centella asiatica). Most of the cosmetic products on the market come from synthetic products that have the potential to cause side effects such as pruritus and local irritation. Hair tonic preparations were chosen because they are suitable for topical use on hair, are easier to apply and are less sticky than semisolid preparations. This study aims to make a hair tonic preparation formula with a combination of fragrant pandanus extract and centella that meets the stability test. The combination formula used is the ratio of fragrant pandanus and centella $F 1$ (kontrol), $F$ II (2:3), F III (2,5:2,5), F IV (3:2). The stability test using the cycling test showed that all formulas were good oranoleptically, the pH test value was between 5.576.16, the viscosity test value was 2.47-2.83 cps. The results showed that all formulas of the combination of fragrant pandanus extract and centella met the stability test.

\section{PENDAHULUAN}

Permaslahan umum rambut rontok sekarang ini meningkat yang menyebabkan kecemasan dan stres untuk individu yang mengalaminya ${ }^{1}$. Penggunaan tanaman obat ewasa ini sangat populer dan semakin disukai oleh masyarakat. hal ini disebabkan karena disamping harganya murah, mudah didapat, juga mempunyai efek samping yang relatif sedikit ${ }^{2}$. Ada beberapa tanaman yang secara empirik digunakan oleh masyarakat untuk merangsang pertumbuhan rambut $^{3}$. Hasil pengembangan produk yang tersedia di pasar menggunakan bahan alami dalam bentuk formulasi herbal digunakan sebagai tonik rambut ${ }^{4}$.

Salah satu tanaman yang secara empiris dapat dimanfaatkan sebagai perawatan rambut adalah daun pandan wangi (Pandanus amaryllifolius Roxb). Daun pandan merupakan bahan alami yang mudah ditemukan dan sering digunakan masyarakat terutama sebagai penambah aroma pada makanan $^{5}$. Khasiat tanaman pandan wangi 
sudah banyak dikenal mulai dari penggunaannya sebagai tonikum, rematik, myalgia, sakit disertai gelisah, rambut rontok, dan menghitamkan rambut ${ }^{6,3}$.

Salah satu tanaman liar yang dimanfaatkan dari alam secara luas adalah Centella asiatica. Hasil penelitian terhadap pegagan menunjukkan ekstrak herba pegagan mempunyai efek pertumbuhan rambut pada kelinci jantan ${ }^{7}$.

Kombinasi dari kedua ekstrak tanaman ini yang digunakan sebagai penumbuh rambut belum dilakukan. Bentuk sediaan hair tonik dipilih karena sediaan ini cocok untuk penggunaan topikal pada rambut, selain itu sediaan hair tonik lebih mudah pengaplikasiannya dan tidak lengket dibandingkan dengan sediaan semisolid jadi tidak meninggalkan lapisan tipis yang dapat menyebabkan ketombe.

Berdasarkan hal diatas, peneliti tertarik untuk melakukan penelitian dengan membuat formulasi kombinasi ekstrak daun pandan wangi dan ekstrak herba pegagan dengan harapan mendapakan formula yang memenuhi syarat stabilitas.

\section{METODE PENELITIAN}

\section{Alat}

Alat yang digunakan dalam penelitian ini adalah Timbangan analitik, Rotary Evaporator, cawan penguap, $\mathrm{pH}$ meter, Viscometer ostwold; blender; lemari pendingin, Kertas saring whatman, kain flanel, ayakan mesh 60, waterbath, oven dan alat-alat gelas (Pyrex®).

\section{Bahan}

Bahan yang digunakan dalam penelitian ini adalah ekstrak daun pandan wangi dan herba pegagan, etanol $96 \%$, propilen glikol, tween 80 , metil paraben, $\mathrm{Na}_{2}$ EDTA, mentol, sodium metabisulfit, aquadest, pereaksi-pereaksi untuk skrining fitokimia; pereakasi Mayer, Dragendorff dan Lieberman-Bourchard, serbuk logam magnesium, toluen.

\section{Pengumpulan dan Penyiapan Simplisia}

Daun pandan wangi dan herba pegagan diperoleh dari daerah Kecamatan Karangjaya, Kabupaten Tasikmalaya, Jawa Barat. Daun pandan wangi yang dipakai adalah daun dari tumbuhan yang sudah berusia empat bulan. Herba pegagan yang dipakai adalah seluruh bagian tanamannya. Determinasi tanaman dilakukan di Daun Pandan dan Herba Pegagan di Determinasi di LIPI Cibinong

Simplisia yang telah didapatkan di sortasi basah, kemudian dicuci menggunakan air mengalir, ditiriskan kemudian dirajang. Simplisia yang telah dilakukan perajangan kemudian dikeringkan dalam oven dan dilakukan sortasi kering. Simplisia yang telah kering kemudian di serbuk sampai halus dengan menggunakan ayakan mesh $60^{8}$.

\section{Proses Ekstraksi}

Proses ekstraksi daun pandan wangi dan herba pegagan dengan etanol 96\%, serbuk simplisia ditimbang masing-masing sebanyak sebanyak 200 gram, dilakukan secara bertahap dengan merendam serbuk simplisia 200 gram dalam 2 liter etanol 96\% selama 2 hari, diaduk setiap 6 jam sekali kemudian disaring menggunakan kain flannel. Filtrat dipekatkan dengan rotary evaporator pada suhu $50^{\circ} \mathrm{C}$, lalu ekstrak dikentalkan ${ }^{8}$.

\section{Penapisan Fitokimia}

Penapisan fitokimia ekstrak daun pandan wangi dan herba pegagan dilakukan untuk mengetahui senyawa metabolit sekunder yang terkandung pada ekstrak meliputi Uji Flavonoid, tanin, triterpenoid, saponin dan alkaloid ${ }^{9}$.

\section{Formulasi Hair Tonic}

Pembuatan sediaan dapat dilakukan beberapa tahap yaitu 1) Larutkan tween 80 dalam dalam etanol hingga larut, tambahkan ekstrak aduk hingga larut sempurna. 2) 
Larutkan sodium metabisulfit dan dinatrium EDTA dalam aquadest hingga larut. Campurkan dengan larutan nomor 1, aduk hingga homogen. 3) Larutkan masing-masing metil paraben dan mentol dalam etanol hingga larut. Kemudian mencampurkan keduanya, aduk homogen. Menambahkan propilen glikol sedikit demi sedikit aduk hingga homogen. 4) Menambahkan larutan nomor 2 ke larutan nomor 3, aduk homogen. 5) Tambahkan aquadest sampai $100 \mathrm{ml}^{10}$.

Tabel 1. Formula hair tonic Kombinasi Ekstrak Daun Pandan dan Herba Pegagan

\begin{tabular}{|c|c|c|c|c|c|c|}
\hline \multirow{2}{*}{ No } & \multirow{2}{*}{ Bahan } & \multicolumn{4}{|c|}{ Jumlah bahan yang digunakan (\%) } & \multirow{2}{*}{ Keterangan } \\
\hline & & F I (Kontrol) & F II & F III & F IV & \\
\hline 1 & $\begin{array}{l}\text { Ekstrak daun } \\
\text { pandan }\end{array}$ & - & 2 & 2,5 & 3 & Zat aktif \\
\hline 2 & $\begin{array}{l}\text { Ekstrak herba } \\
\text { pegagan }\end{array}$ & - & 3 & 2,5 & 2 & Zat aktif \\
\hline 3 & Etanol 96\% & 30 & 30 & 30 & 30 & Pelarut \\
\hline 4 & Propilen glikol & 10 & 10 & 10 & 10 & Humektan \\
\hline 5 & Tween 80 & 1 & 1 & 1 & 1 & Surfaktan \\
\hline 6 & $\begin{array}{l}\text { Methyl } \\
\text { paraben }\end{array}$ & 0,075 & 0,075 & 0,075 & 0,075 & Pengawet \\
\hline 7 & $\mathrm{Na}_{2}$ EDTA & 0,025 & 0,025 & 0,025 & 0,025 & Pengkhelat \\
\hline 8 & Menthol & 0,100 & 0,100 & 0,100 & 0,100 & Pendigin \\
\hline 9 & $\begin{array}{l}\text { Sodium } \\
\text { metabisulfit }\end{array}$ & 0,200 & 0,200 & 0,200 & 0,200 & Antioksidan \\
\hline 10 & Aquadest & Add 100 & Add 100 & Add 100 & Add 100 & Pelarut \\
\hline
\end{tabular}

\section{Uji Stabilitas}

Uji stabilitas sediaan metode cycling test, yaitu cara mempercepat evaluasi sediaan dalam penyimpanan selama beberapa waktu pada suhu yang lebih tinggi daripada normal. Sediaan hair tonic disimpan pada suhu $\pm 4^{\circ} \mathrm{C}$ selama 24 jam lalu dikeluarkan dan ditempatkan pada suhu $\pm 40^{\circ} \mathrm{C}$ selama 24 jam, pelakuan ini terhitung satu siklus, pelakuan ini terhitung satu siklus. Pada pengujian kali ini dilakukan sebanyak 6 siklus dilakukan evaluasi yaitu uji organoleptik, $\mathrm{pH}$ sediaan dan uji viskositas

\section{HASIL}

Hasil determinasi menunjukkan bahwa sampel yang digunakan adalah daun pandan wangi (Pandanus amaraliifolius Roxb.) Suku Pandanaceae dan herba pegagan (Centella asiatica) suku Apiaceae daun pandan wangi (Pandanus amaraliifolius Roxb.)

Serbuk Daun Pandan Wangi berwarna hijau, ekstrak etanol yang dihasilkan adalah ekstrak kental berwarna hijau pekat, seberat 31,4 gram, dengan rendemen $15,7 \%$. Sedangkan herba pegagan menghasilkan serbuk berwarna hijau kecoklatan dengan ekstrak kental berwarna hijau kekuningan dengan berat 28,3 dengan 14,15\% .

Kemudian sampel dilakukan penapisan fitokimia untuk mengetahui secara kualitatif senyawa metabolit sekunder yang terdapat dalam simplisia daun pandan wangi dan herba pegagan. Daun pandan wangi mengandung flavonoid, tanin, saponin, alkaloid. Sedangkan Herba pegagan mengandung flavonoid, tanin, saponin, triterpenoid. 


\section{Hasil Uji Stabilitas Sediaan}

Uji Organoleptik

Tabel 2 Pengujian Organoleptis cycling test uji selama 6 siklus

\begin{tabular}{llllllll}
\hline \multirow{2}{*}{ Formula } & \multirow{2}{*}{ Pengamatan } & \multicolumn{7}{c}{$\mathbf{1}$} & \multicolumn{2}{c}{ Siklus } \\
\cline { 2 - 8 } $\begin{array}{l}\text { F I } \\
\text { kontrol }\end{array}$ & Bau & Khas & Khas & Khas & Khas & Khas & Khas \\
\cline { 2 - 8 } & Warna & Bening & Bening & Bening & Bening & Bening & Bening \\
\hline FII & Bau & Khas & Khas & Khas & Khas & Khas & Khas \\
\cline { 2 - 8 } & Warna & Hijau & Hijau & Hijau & Hijau & Hijau & Hijau \\
& & Kekuningan & Kekuningan & Kekuningan & Kekuningan & Kekuningan Kekuningan \\
\hline FIII & Bau & Khas & Khas & Khas & Khas & Khas & Khas \\
\cline { 2 - 8 } & Warna & Hijau & Hijau & Hijau & Hijau & Hijau & Hijau \\
\hline FIV & Bau & Khas & Khas & Khas & Khas & Khas & Khas \\
\cline { 2 - 8 } & Warna & Hijau & Hijau & Hijau & Hijau & Hijau & Hijau \\
& & Kecoklatan & Kecoklatan & Kecoklatan & Kecoklatan & Kecoklatan & Kecoklatan \\
\hline
\end{tabular}

\section{Pengujian pH Setelah Cycling Test}

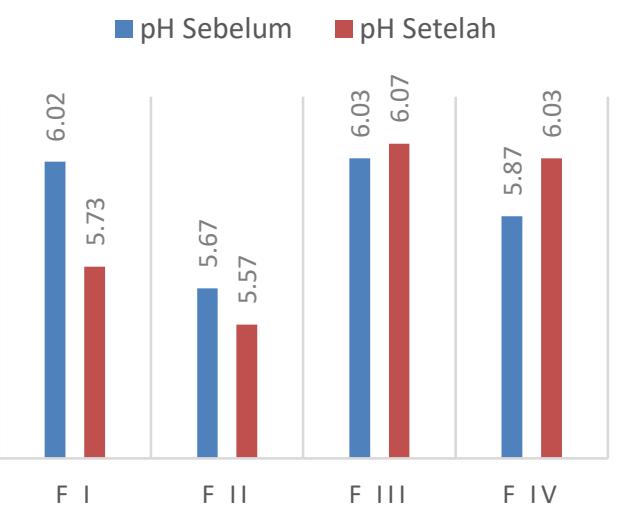

Gambar 1. Diagram Nilai pH Setelah Uji Cycling Test

\section{Pengujian Viskositas Setelah Cycling Test}

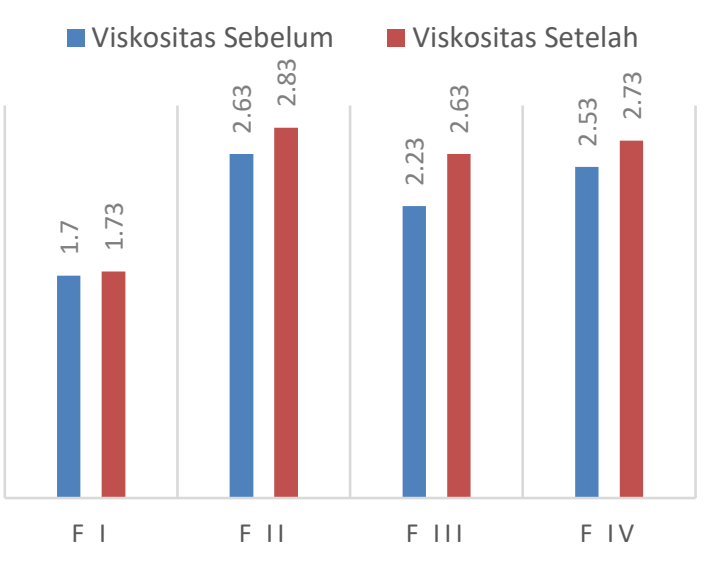

Gambar 2. Diagram Nilai Viskositas Setelah Uji Cycling Test

\section{PEMBAHASAN}

Sediaan tonik rambut yang dihasilkan berwarna hijau kekuningan merupakan perpaduan dari warna ekstrak daun pandan wangi yang mendominasi warna sediaan, dikombinasikan dengan ekstrak herba pegagan yang berwarna hijau kecoklatan. Bau yang dihasilkan sediaan yang dihasilkan khas ekstrak yang bercampur dengan bau mentol, sehingga menciptakan kesan yang segar dari sediaan. Sediaan yang dihasilkan jernih dan homogen karena semua bahan dalam formulasi dapat larut dengan baik dalam pembawanya.

Hasil uji stabilitas menggunakan metode Cycling Test dihasilkan nilai $\mathrm{pH}$ yang menunjukkan adanya penurunan dan juga peningkatan nilai $\mathrm{pH}$. Data nilai $\mathrm{pH}$ yang diperoleh kemudian diuji statistik dengan menggunakan Paired-Sample $T$ Test untuk mengetahui adanya perbedaan signifikan sebelum dan sesudah diuji. Berdasarkan uji dengan menggunakan didapatkan nilai signifikan sebesar 0,639 hal ini menunjukkan bahwa tidak adanya perbedaan signifikan karena nilai $\mathrm{p}>0,05$. Perubahan nilai $\mathrm{pH}$ masih dalam rentang $\mathrm{pH}$ yang sesuai 
spesifikasi $\mathrm{pH}$ yang diinginkan yaitu antara 37.

Nilai viskositas sediaan hair tonic kombinasi ekstrak daun pandan dan herba pegagan setelah dilakukan uji stabilitas cycling test mengalami perubahan. Pada tiap formula mengalami peningkatan nilai viskositas dikarenakan adanya penguapan pelarut pada saat penyimpanan. Pada pengukuran viskositas sediaan hair tonic kombinasi ekstrak daun pandan dan herba pegagan menunjukkan peningkatan nilai viskositas pada rentang 2,63-2,83 cps. Untuk mengetahui adaya perbedaan bermakna antar nilai vikositas sebelum dan sesudah uji stabilitas cycling test, maka dilakukan uji statistik dengan uji Paired Sample T Test dengan menggunakan SPSS. Berdasarkan uji statistik masing-masing formulaa mengalami perubahan signifikan. Hal ini dikarenakan hasil uji anlisis menunjukkan nilai signifikansi $\mathrm{p}=0,005(\mathrm{p}<0,05)$.

\section{KESIMPULAN DAN SARAN}

Sediaan hair tonic kombinasi ekstrak daun pandan wangi (Pandanus amaryllifolius Roxb.) dan herba pegagan (Centella asiatica) memenuhi syarat stabilitas.

Untuk peneliti selanjutnya diharapkan melakukan pengembangan penelitian dengan uji aktivitas pertumbuhan rambut dari sediaan kombinasi ekstrak daun pandan wangi dan herba pegagan

\section{UCAPAN TERIMAKASIH}

Penelitian ini didanai oleh dana hibah internal Universitas Perjuangan. Terima kasih yang sebesar-besarnya penulis sampaikan kepada semua pihak yang terlibat selama penelitian ini berlangsung sehingga penelitian ini berjalan lancar.

\section{DAFTAR PUSTAKA}

1. Shannon H, Wilma B. Diffuse hair loss: its triggers and management. Cleve Clin J Med. Published online 2009:361-7.
2. Nnoruka NE. Hair loss: Is there a relationship with hair care practices in Nigeria? Int J Dermatol. 2005;44(SUPPL. 1):13-17.

doi:10.1111/j.1365-4632.2005.02801.x

3. Anwar K, Wathan N, Triyasmono L. Efek Tonik Ekstrak Etanol Daun Pandan Wangi (Pandanus Amaryllifolius Roxb.) pada Mencit Jantan. In: Konferensi Nasional Sains dan Aplikasinya (KNSA); 2011:381-385. Accessed February 5, 2021.

4. Lucky AW, Piacquadio DJ, Ditre CM, et al. A randomized, placebo-controlled trial of $5 \%$ and $2 \%$ topical minoxidil solutions in the treatment of female pattern hair loss. $J$ Am Acad Dermatol. 2004;50(4):541-553.

doi:10.1016/j.jaad.2003.06.014

5. Jimtaisong A, Krisdaphong P. Antioxidant activity of Pandanus amaryllifolius leaf and root extract and its application in topical emulsion. Trop $J$ Pharm Res. 2013;12(3):425-431. doi:10.4314/tjpr.v12i3.23

6. Prameswari OM, Widjanarko SB. Uji Efek Ekstrak Air Daun Pandan Wangi Terhadap Penurunan Kadar Glukosa Darah dan Histopatologi Tikus Diabetes Melitus. J Pangan dan Agroindustri. 2014;2(2):16-27.

7. Sulastri L, Indrawati T, Taurhesia S. UJI AKTIVITAS PENYUBUR RAMBUT KOMBINASI EKSTRAK AIR TEH HIJAU DAN HERBA PEGAGAN. Pharmaciana. 2016;6(1):39-46.

doi:10.12928/pharmaciana.v6i1.3194

8. Ditjen POM. Parameter Standar Umum Ekstrak Tumbuhan Obat Cetakan Pertama.; 2000.

9. Harborne J. Metode Fitokimia : Penuntun Cara Modern Menganalisis Tumbuhan (Ahli Bahasa: Kosasih Padmawinata \& Iwang Soediro). 2nd ed. (Padmawinata K, Soediro I, eds.). ITB; 1996. 
10. Septiani G, Anny, Agung. UJI AKTIVITAS PERTUMBUHAN

RAMBUT KOMBINASI EKSTRAK

ETANOL DAUN PANDAN WANGI

(Pandanus amaryllifolius Roxb.) DAN

DAUN LIDAH MERTUA (Sansevieria

trifasciata Prain.). J Pharmacopolium.

2018;1(2). doi:10.36465/jop.v1i2.327 